UDK 781.4Žebre

Karmen Salmič

Univerzitetna knjižnica, Maribor

University Library, Maribor

\title{
Melodične in harmonske tonske strukture v orkestralnih skladbah Demetrija Žebreta
}

\author{
Melodic and Harmonic Tone-Structures \\ in Demetrij Žebre's Orchestral Pieces
}

Ključne besede: Demetrij Žebrè, orkestralna glasba, melodika in harmonija, glasbene analize, slovenska glasba, 20. stoletje

\section{IZVLEČEK}

Pričujoči glasbeno-analitični prispevek obravnava spreminjanje melodičnih in harmonskih tonskih struktur ter njihovo medsebojno učinkovanje v osmih orkestralnih skladbah Demetrija Žebreta, učenca Slavka Osterca in enega od zmerno modernistično usmerjenih ustvarjalcev slovenske orkestralne glasbe v 1. polovici 20. stoletja. Analiza skladb je pokazala, da se v Žebretovi glasbi "staro" druži z "novim" na različne načine. Večinoma so elementi stare tonalnosti vkomponirani v novo teksturo, zvočnost, stavčno gradnjo in ritmičnometrične kombinacije na nekaj različnih načinov. Skladbe iz časa skladateljevega iskanja radikalnejših rešitev v smeri odklona od tonalnosti pa se skrajno približajo meji neurejene atonalnosti, brez poskusa njihove dodekafonske sistematike.
Key words: Demetrij Žebrè, orchestral music, melody and harmony, music analyses, Slovenian music, $20^{\text {th }}$ Century

\section{ABSTRACT}

This analytical article on music deals with the variation of melodic and harmonic tone structures and their reciprocal effects in eight orchestral pieces by Demetrij Žebre - a student of Slavko Osterc and one of the moderately modernistic creative authors of Slovene orchestral music in the first half of the $20^{\text {th }}$ century. The analysis shows that in Žebre's music "old" meets "new" in various ways. The elements of the old tonality are mostly included within a new texture, sound, movement structure and rhythmically metrical combinations in several different manners. The compositions from the composer's period of pursuit of more radical solutions in terms of deviation from tonality almost reach the boundaries of a disoriented atonality without an attempt of their dodecaphonic organization. 
Melodične in harmonske tonske strukture - izbira tonskih vrst v horizontali in vertikali, način njihovega povezovanja (strukturiranja) v melodiki kot v sozvočnih kombinacijah ter način njihovega skupnega in medsebojnega učinkovanja v obeh razsežnostih zvočnega prostora - so pomemben indikator novuma $\mathrm{v}$ glasbi 20. stoletja. Po prelomu in s koncem funkcionalne tonalnosti gre v skrajno smer doslednega odstranjevanja zadnjih tonalnih elementov iz stavka le nekaj v atonalnost zagledanih skladateljev (med drugimi del nove dunajske šole). Zgledi za svobodno (1908) in urejeno atonalnost so do leta 1923 postavljeni, vendar se veliko skladateljev prve polovice 20. stoletja odloči za nov način strukturiranja starega gradiva oziroma uporabo nekaterih elementov starega sistema. Popolna svoboda izbire tonskih višin v horizontali in vertikali ter njihovih vezav $-\mathrm{z}$ ohranitvijo tonikalnih težišč (bodisi središčnih tonov) ali brez njih - kot posledica emancipacije disonance in enakovrednosti dvanajstih kromatičnih tonov odpre široko polje možnosti tovrstnih odnosov in omogoči raznotere individualne rešitve.

Tudi v glasbi Demetrija Žebreta $(1912-1970)^{1}$, dirigenta in skladatelja, učenca Slavka Osterca, se tako "staro" druži z "novim" na različne načine. Večinoma so elementi stare tonalnosti vkomponirani v novo teksturo, zvočnost, stavčno gradnjo in ritmično-metrične kombinacije na nekaj različnih načinov; skladbe iz časa skladateljevega iskanja radikalnejših rešitev v smeri odklona od tonalnosti pa se skrajno približajo meji neurejene atonalnosti in atematičnosti, brez poskusa dodekafonske sistematike. Predstavljeni bodo izsledki analiz melodično-harmonskih struktur zgolj z ozirom na njihovo tonsko vsebino $\mathrm{v}$ osmih skladateljevih orkestralnih skladbah, nastalih med leti 1932 in 1949. Z izjemo Suite so vse obravnavane skladbe napisane za simfonični orkester. Kot drugačni zvrsti s svojimi specifičnostmi sta bila iz analize izvzeta Concertino za klavir in orkester (1946) ter vokalno-instrumentalno delo Maja in morje za glas in orkester (1944).

Prerez Žebretovega orkestralnega opusa skozi to perspektivo, čeprav gre le za fragmentaren in ozek izsek iz možne množice različnih glasbeno-analitičnih obravnav, bo delno nakazal tudi spreminjanje sloga in skladateljevih kompozicijskih nazorov od študijskih let na visoki stopnji Državnega konservatorija v Ljubljani (1929-1934) do leta 1949, ko je njegovo pero za zmeraj obležalo. Izsledki celovitejše obravnave njegovih orkestralnih skladb, ki pa na tem mestu ne bodo predstavljeni, so pokazali, da je začetku pod vplivom učitelja Osterca (Suita) sledil odmik $\mathrm{v}$ radikalno obravnavo horizontale in vertikale med ter takoj po študiju v Pragi pri Josefu Suku in Aloisu Hábi (Tek, Toccata), le temu epizoda impresionistične zvočnosti (Bacchanale, Tri vizije), tej pa "vrnitev" k trdni (klasicistični) oblikovni logiki in motivično-tematični enovitosti (Svobodi naproti, Žalna glasba, Allegro risoluto-marciale).

V Suiti za mali orkester (1932) sta povezani dve precej skrajni možnosti "tonalno-atonalne" polarnosti. V melodiki so to svobodno kromatično zasnovane melodične linije, s težnjo neponavljanja tonske vsebine in hitrega zapolnjevanja kromatičnega prostora ${ }^{2}$ nasproti linijam, ki so diatonične in tonalno jasno osrediščene, nekatere celo iz tonov durovega trozvoka ${ }^{3}$. Najbolj tipična pa je melodična linija, ki je razrezana na kratke tonalne segmente. Kot celota je sicer po tonski vsebini svobodno kromatična, vendar nenehnim spreminjanjem tonikalnih centrov navkljub je jasnost tonalne asociativnosti ${ }^{4}$ njenih segmentov tolikšna, da učinkuje zelo znano, kot politonikalna tonalna lepljenka. Različna tonalna (modalna) območja tonov ali tonikalna žarišča so nanizana v horizontali svobodno, brez tonalno-funkcionalne povezanosti,

\footnotetext{
Pričujoči prispevek je prirejeno poglavje iz magistrske naloge avtorice, ki je nastala na Oddelku za muzikologijo FF v Ljubljani pod mentorstvom izr. prof. dr. Matjaža Barba; raziskovanje na to temo pa se je začelo še pod mentorstvom red. prof. dr. Andreja Rijavca. Več o melodiki in harmoniji, o Demetriju Žebretu in njegovi orkestralni glasbi gl. K. Salmič Kovačič: Orkestralni opus Demetrija Žebreta. Ljubljana, [samozal.], 2006.

Gl. npr. 1. st., linijo solo trobente, t. 11-17.

3 Gl. 2. st., linijo solo trobente, t. 17-29 z dorsko toniko na tonu g, potem na b ter 1. st., linijo trobent (t. 24-27), fagotov (t. 28-31), flavt (t. 31-35), klarinetov (t. 35-37) iz tonov durovega sekstakorda.

To so lahko, denimo, prvi trije toni durove lestvice. Gl. 2. st. vl. I, t. 4-16.
} 
bistvena pa je vertikalna sočasnost ("polifonija") različno tonikalno osrediščenih in tonsko vsebinsko raznolikih ter spreminjajočih se subteksturnih plasti, tako da so vertikalna disonačna trenja med njimi "slučajni" izid načrtovane medlinijske politonalne politonikalnosti (zelo znana je ta tehnika pri Šostakoviču ali Prokofjevu).

Pri Teku (1935) postane popolno (a svobodno) zapolnjevanje kromatičnega tonskega prostora osnovno vodilo $\mathrm{v}$ horizontali in vertikali. Vsaka melodična fraza teži $\mathrm{k}$ temu posebej, prav tako spremljevalne teksturne plasti (linije), kot tudi melodično mobilni ritmični ostinati. Kompleten zvočni prostor se kromatično zapolni že $v$ treh ali štirih taktih, medtem ko traja zvrstitev dvanajstih tonov, ki niso soodvisni v zaporedju kot pri dodekafonski tehniki, $\mathrm{v}$ horizontalnem poteku glasov nekaj taktov več, odvisno od dolžine fraz. Ker je tekstura izrazito polifonska, kontrapunktično naslojevanje neodvisnih melodičnih linij in linearno mišljenje pa bistvena ideja skladbe, je vir nastanka akordskih struktur treh vrst. Prve so akordske subteksturne plasti, ki so bolj izjema v izrazito linearnem zvočnem okolju, skladatelj pa jih uporabi za zvočno zgoščevanje glasbenega toka v progresijah ali na viških. Druge so sozvočja celotne vertikale, ki nastajajo na "spojnih" mestih (kadencah), ob zaključku ene in začetku naslednje fraze ali ob koncu nekega odseka. Ta mesta so kljub razgibanemu polifonskemu dogajanju znotraj odseka (različnost dolžin melodičnih linij) jasno prepoznavna in njihova vertikalna struktura je dobro premišljena. Še vedno to niso homofonski akordski sklopi, ampak sozvočja kot posledica vertikalne sočasnosti lineranih komponent. Kot mesta s kadenčno funkcijo jih Žebrè obravnava v smislu sprostitve, zato so pogosto terčno razložljiva in poliakordsko (politonalno) diatonična oziroma razširjeno tonalna. Lahko pripadajo eni diatonični lestvici, tedaj sežejo do sedmerozvokov, ali pa so kromatična 5 , a kot kombinacija več diatoničnih tonalnih struktur (trozvokov, septakordov) in so tako tudi instrumentacijsko povezana $\mathrm{v}$ teksturi ( $\mathrm{v}$ posameznih zvočnih skupinah ali subteksturnih plasteh). Vendar je njihova vertikalna razporeditev pogosto neterčna (izstopajo intervali sekunde in kvarte). Tudi vrsta in velikost večzvoka je odvisna od mesta napetosti v skladbi - ali gre za začetek progresije, njen višek ali za sproščanje. Stavek je kljub temu atonalen, saj omenjena kadenčna mesta nimajo nobene zveze z ostalim atonalnim (kromatičnim) okoljem niti nimajo funkcije tonalnega centra, cilja, h kateremu glasba teži, ampak z njimi skladatelj ublaži disonančnost vertikalnih struktur, ki nenehno nastajajo kot tretja oblika sozvočij v sočasnem linearnem poteku polifonsko naslojenih atonalnih melodičnih linij. Kadenčne akordske strukture (vertikalne zareze v skladbi) so tudi edine, ki na opisan način ohranjajo vez s tradicionalno tonalnostjo. Sicer je disonanca emancipirana v enakovrednosti vseh kromatičnih tonov horizontale in vertikale. Melodične fraze so po dolžini zelo raznolike, vendar je za vse značilno, da so daljše in nesimetrične strukture (5, 7, 11, 14 itd. taktov), upirajoče se periodični gradnji.

Tudi v intervalni sestavi melodičnih linij se skladatelj izogiba tradicionalnim intervalom (tercam, sekstam) in izpostavlja sekunde, kvarte ter njihove obrate (septimo, kvinto). Prevladujejo intervali do kvinte, večji skoki so v manjšini. Ideja tonskega polja (enotna tonska vsebina vertikale in horizontale) je sicer v Teku prisotna, v kolikor temeljijo odseki na popolni kromatični domeni, vendar slednji med seboj niso jasno teksturno (vertikalno) zamejeni.

Konstrukcijska logika strukturiranja tonske višine v Toccati (1936) je podobna. Popolno zapolnjevanje kromatičnega prostora je v obeh skladbah prilagojeno mestu v napetostnem toku skladbe: počasnejše je na začetku progresij (nekaj taktov) ali v statičnih odsekih, hitrejše na koncu progresij oziroma na viških (že v enem taktu), kar je v komplementarnem součinkovanju s teksturnim zgoščanjem in redčenjem.

Na višku napetosti v t. 393-394, denimo, je ležeči akord celotne vertikale (ena redkih homofonski mest) sestavljen iz dvanajstih kromatičnih tonov, vendar je v teksturi razdeljen med zvočne skupine na trdoveliki C-durov septakord, trdoveliki D-durov septakord in b-molov undecimakord. 
Bistvena sprememba $\mathrm{v}$ povezovanju horizontalnih in vertikalnih tonskih struktur se zgodi $\mathrm{v}$ Žebretovem orkestralnem opusu pri baletu oziroma simfonični sliki v treh stavkih Dan (1938 -1942), ki jo poznamo po imenom Bacchanale ${ }^{6}$. Rešitev za enovitost tonske vsebine v obeh razsežnostih prostora (po zgledu stare tonalnosti) najde skladatelj v tonskih poljih, na katera $\mathrm{z}$ vertikalnimi "zarezami" (večinoma tudi teksturnimi) "razreže" skladbo. Zgled za to in za teksturo, ki to omogoči na najbolj učinkovit način, najde pri impresionistih. Polifonsko naslojevanje neodvisnih melodičnih linij zamenja vrsta teksture, ki zelo jasno loči melodično linijo (redkokdaj se ji pridruži kontrapunktična) od ostalega zvočnega okolja. To postane namreč "negibno" - sestavljajo ga melodično, harmonsko in ritmično statične ostinatne subteksture (ponavljajoče se figure, pasaže, akordi). Učinkujejo kot zvočne ploskve s svojo zvočno barvo, saj so za razliko od (večinoma ene) melodične linije številčnejše in izvajalsko dodeljene različnim skupinam glasbil oziroma posameznim glasbilom. Med seboj ritmično in melodično "kontrapunktirajo" (so različne), spremenijo pa se z nastopom novega tonskega polja, ta pa večinoma z nastopom nove melodične fraze. Ker tonsko polje zamenja pojem stare tonalitete (medsebojno odvisna oziroma zaključena zbirka tonov določenega odseka v melodiji in harmoniji), se ta včasih spremeni tudi med potekom ene melodične linije, če ta linearno "modulira". Tedaj ostanejo spremljevalne zvočne ploskve ritmično enake, minimalno pa se spremeni njihova tonska vsebina, prilagojena novemu polju. Celota učinkuje kot "tkanina" iz enako močnih niti horizontalno naslojenih "utripajočih" zvočnih ploskev (ostinatna "polifonija") brez harmonskega cilja, nad katero se dvigajo melodične fraze, ki členijo skladbo.

Tonska vsebina melodije in spremljave je redko identična, večinoma se razlikuje v enem ali nekaj tonih ter šele skupaj tvori lestvično osnovo polja. Ta nikoli ni diatonično tonalna (v tradicionalnem pomenu), ampak iz novih sestavljenih lestvic različnih dolžin (od šest do dvanajsttonskih), odvisno od mesta napetosti v skladbi. Lahko pa je melodična linija povsem tradicionalne tonske vsebine (durova lestvica, harmonična in melodična molova lestvica), ali pa temelji na pentatoniki, durovem, molovem tetrakordu, celotonski lestvici, starocerkvenem modusu, na lestvici iz dveh tetrakordov dveh različnih lestvic ${ }^{7}$. Predvsem izbira skladatelj takšne (večznačne) lestvične osnove, ki omogočajo "tonalno" polivalentnost (vključno s pentatonsko, celotonsko in modalnimi lestvicami). Tonalno polivalentna je lahko tudi sama melodična linija, največkrat pa pride tonalna večznačnost do izraza v odnosu med melodijo in spremljevalnimi ostinatnimi zvočnimi ploskvami. Vendar zakoni dur-molove (funkcionalne) tonalosti nikakor ne veljajo več - posamezne tradicionalne lestvice, lestvični segmenti, akordi ali kadenčni koraki so zgolj stari gradniki v novem sistemu. Tonsko gradivo je osvobojeno starih vezi in razširjeno z novimi akordskimi strukturami in intervalnimi razmerji. Kvartni akordi imajo denimo enako veljavo kot zaporedje funkcionalno nevezanih durovih trozvokov, basovski korak zvečane kvarte pa je enakovreden kvintnemu. Vsak dobi svoje mesto v skladbi glede na tendenco napetosti določenega odseka. Skladatelj išče nove harmonske (in zvočne) barve v melodiki z nagnjenostjo k modalnosti in molovskemu občutenju, v harmoniki pa s kvartnimi akordi, zvečanimi trozvoki, trdovelikimi septakordi, sekundno razporeditvijo v vertikali in podobno.

Harmonska gostota je pri tej skladbi manjša kot pri Teku in Toccati, prevladujeta štiri in petglasnost, manj in večglasne akorde uporabi skladatelj na mestih manjše oziroma večje napetosti, vendar ne presegajo šestglasja. Akordi so večinoma terčno "sestavljivi", pogosto tudi

6 Obsežna tristavčna orkestralna skladba je bila do danes izvajana pod naslovom Bacchanale, z domnevno letnico nastanka 1933. Vendar skoraj identična partitura baleta Dan (1938-1942), ki je le njena instrumentacijska dodelava, dokazuje, da gre za isto skladbo. Poleg tega rokopisni zaznamek v preostanku skladateljeve zapuščine, ki se nahaja skupaj z zapuščino Ksenije Vidali v Slovenskem gledališkem muzeju, da "partitura Bacchanala ne obstaja", indicira domnevo, da je Žebrè skladbo uničil. Dokaz o tem, da je za časa študija pri Slavku Ostercu zares napisal skladbo pod tem naslovom (zelo verjetno leta 1933), pa je rokopisna ocena le-te izpod peresa Emerika Berana, tedanjega člana komisije pri izpitih Osterčevih učencev (hrani jo Univerzitetna knjižnica Maribor v okviru Beranove zapuščine).

Denimo drugega tetrakorda melodičnega in harmonskega d-mola in g-mola ali združitve npr. istoimenske durove in molove lestvice, 1. st., t. $13-18$. 
tradicionalno tonalni, vendar neodvisni od okolice. Pomembna je tudi njihova razporeditev v teksturi in instrumentaciji, kjer skladatelj zaostruje vertikalo z sekundno, kvartno, kvintno, septimno ali mešano razporeditvijo tonov.

Melodika se razlikuje od tiste v Teku in Toccati po intervalni vsebini, obliki, obsegu in stavčni gradnji. Prevladujejo sekundni postopi, terčni koraki, zaporedni skoki so redkejši (med temi sta pogosti čista kvarta in kvinta). Melodična krivulja ima večinoma obliko počasi ali hitro dvigajočega se loka (navzgor ali navzdol), premočrtnega vzpona ali pa kroži na mestu, odvisno od značaja odseka. Zaradi raznolike izraznosti skladbe se tudi njihov obseg zelo razlikuje (od štirih tonov do dveh oktav ali več); glede na to se spreminja tudi vsebnost zaporednih skokov. Pojavljajo se tudi sekvencirane ponovitve melodičnih fraz, štiritaktij, čeprav prevladuje variacijskost motivike - razvijanje novih melodičnih členov, ki so s predhodnimi v bolj ali manj ohlapni motivični povezavi, vendar na tradiciji bližji način kot v Teku in Toccati. Pojavlja se že tip melodike orientalskega značaja z metrično asimetrijo, vračanjem enemu poudarjenemu tonu, vmesnim okraševanjem (drobljenjem na manjše ritmične vrednosti, figure), modalnim prizvokom, ozkim obsegom in kroženjem na mestu, kar je ena od značilnosti Treh vizij.

Kljub zunajtonalni izbiri tonskih struktur $\mathrm{v}$ horizontali in vertikali in svobodni obravnavi njihovih odnosov je v primerjavi s prejšnjima dvema skladbama očiten odločen korak k bolj diatoničnim in blagozvočnim tonskim strukturam ter njihovim razmerjem, s tem pa k bolj "konsonančnim" in "tonalnim" zvokom, z izdatno vključitvijo elementov starega dur-molovega sistema. Bistven razlika pa je tudi v ponavljanju tonske višine v melodiki, ki je pri Teku in Toccati popolnoma odsotna in se ji skladatelj izogiba tudi v ostinatnih teksturah (v Toccati malo manj). Novo je tudi že opisano urejanje glasbenega prostora $\mathrm{v}$ tonska polja (vertikalno) in $\mathrm{v}$ različno instrumentirane zvočne ploskve (horizontalno) okoli melodične linije in njenih občasnih kontrapunktov.

Za Tri vizije (1939-1943) velja podobna strukturna logika z razliko, da glede na izbrušen in enovit (impresionistični) izraz skladatelj omeji izbor tonskih vrst na manjštevilčne (do 8 tonov) in pogosteje uporabi celotonske, pentatonske, durove in molove strukture v melodični liniji ali ostalih zvočnih plasteh. Kromatičnost iz Bacchanale še omili z bolj diatoničnimi vrstami, tradiciji bližjimi kombinacijami in "modulira" počasneje iz enega tonskega polja v drugega. Še bolj izostri način tonikalne polivalentnosti (politonalnosti) v vertikali in horizontali z združevanjem več tradicionalno prepoznavnih lestvičnih osnov v eno, ki jih potem politonikalno razslojuje po različnih sočasnih linijah teksture. Izbira zelo sorodne ali po številu kromatičnih tonov bližnje "tonalitete"8. Tudi harmonska gostota je manjša, prevladujeta tri in štiriglasje. Melodične linije so različnih oblik, od arabeskno okrašenih svobodnejšega zamaha do lestvično grajenih in periodično urejenih.

Z logiko tonskih polj skladatelj nadaljuje v Svobodi naproti (1944), Žalni glasbi (1945) in Allegru risoluto marciale (1949), vendar ta ni v več v prvem planu. Zmanjšana je prisotnost (melodično-ritmično) statičnih zvočnih ploskev, ki se pojavljajo le še na skrbno izbranih mestih in so podrejena razgibanemu motivično-tematskemu oblikovanju glasbenega toka, zaradi česar pride do večjega (melodično-harmonskega) aktiviranja posameznih subteksturnih plasti. V ospredju je ideja tonikalne in tonalne večznačnosti iste (diatonične ali kromatične) lestvične osnove tonsko enovitega odseka (dvotaktja, fraze). Če je ta diatonična, teksturo skladatelj različno politonikalno (politonalno) razsloji že z njenimi obrnitvami9 . Če pa razširi tonski prostor "polja" na več kot sedem tonov, ima možnosti za politonikalne in politonalne izpeljave v melodiki in harmonijah še več ${ }^{10}$. Zanimajo ga torej različne podmnožice ene (sedem- do

Npr. G dur, melodični g-mol, e-mol, F-dur, pentatonika iz teh tonov, različne modalne izpeljave iz teh tonalitet.

Npr. toni G-durove lestvice v eni subteksturni plasti tonikizirajo ton $\mathrm{g}, \mathrm{v}$ drugi ton $\mathrm{c}$ - lidijski modus, $\mathrm{v}$ tretji ton e - naravni e-mol

Npr. z združitvijo tonov melodičnega e-mola in melodičnega a-mola dobi domeno desetih tonov - c, cis, d, dis, e, f, fis, g, gis, a, h, iz katerih izpelje melodično linijo $\mathrm{v}$ melodičnem e-molu, drugo v lidijskem na tonu d, tretjo v dorskem modusu na tonu e, t. $7-10$. 
dvanajsttonske) zbirke tonov, ki jih razvrsti v sočasnih teksturnih komponentah. V Svobodi naproti prevladujejo diatonične linearne podvrste (poleg tradicionalnih durovih in molovih lestvic še modalne), pentatonskim in celotonskim se popolnoma izogne, kromatične oziroma iz kratkih tonalnih segmentov (modulirajoče) sestavljene melodične linije pa so izjema. V Žalni glasbi in Allegro risoluto-marciale je kromatika tonskih polj in melodičnih linij pogostejša, odvisna od oblikovne funkcije in mesta napetosti v skladbi. Hitrejše je tudi zaporedno menjavanje diatoničnih segmentov $\mathrm{v}$ horizontali.

Kljub kromatično razširjenemu skupnemu zvočnemu prostoru (ki se od odseka do odseka spreminja po sestavi) so v vseh treh skladbah subteksturne melodične linije in akordske strukture močno tradicionalno asociativne, čeprav razvezane starih pravil vzajemnega učinkovanja. Stavek je harmonsko gibkejši, harmonski ritem pa hitrejši tudi tam, kjer melodično linijo (v tematskih odsekih) spremljajo ostinatne figuralne plasti. Tudi akordske strukture so vsaka zase večinoma tradicionalne, terčno razložljive in diatonične, vendar svobodne v zaporedjih, sočasnih naslojevanjih in (netradicionalni) teksturni razporeditvi. Harmonska gostota se subtilno spreminja od dvozvočja prek trozvokov in septakordov do višjeterčnih akordov, občasno pa zaostri skladatelj vertikalo tudi z netradicionalnimi sozvočji (na mestih povečane napetosti), ki so lahko tudi izid politonalne (poliakordske) zasnove. Glede na pogosto izbiro lidijskega modusa $\mathrm{v}$ melodiki skladbe Svobodi naproti sta strukturno izpostavljena interval zvečane kvarte $^{11}$ in trdoveliki septakord ${ }^{12}$. Interval kvarte marsikje disonančno zaostri vertikalo tudi $\mathrm{v}$ Žalni glasbi, kjer mračno vzdušje izvira iz molovskih lestvičnih osnov, in v melodiki druge teme v Allegro risoluto-marciale, za katero je značilno nihanje med durovsko in molovsko zvočnostjo, razširjeno z opisano kromatiko.

Teme imajo $\mathrm{v}$ vseh treh skladbah pretežno lokasto in precej tradicionalno periodično strukturo; posebnost sta drugi temi v Žalni glasbi in Allegro risoluto-marciale, ki v variacijskem razvijanju oblikujeta daljši lok pri enem od kasnejših nastopov v obliki "melodične" izpeljave. Tako kot postane motivično gradivo teh skladb osnova sonatnemu principu oblikovanja, postanejo tudi melodične in harmonske tonske povezave predmet subtilnega spreminjanja in oblikovanja $\mathrm{v}$ dinamičnih napetostnih procesih kot tudi $\mathrm{v}$ kompleksnem poenotenju mnogoterosti $\mathrm{v}$ vseh strukturnih parametrih. $\mathrm{V}$ tem je iskati največji skladateljev odmik od kompozicijske tehnike Treh vizij v omenjenih opusih.

\section{SUMMARY}

This article deals with the variation of melodic and harmonic tone structures and their reciprocal effects in eight orchestral pieces by Demetrij Žebre, a student of Slavko Osterc. The profile of his works from this perspective also indicates alterations in style and composition principles of the composer from year 1932 to 1949, when he wrote his last piece of music. After the beginning of his career which is influenced by his teacher (Suita) he introduces a radical treatment of horizontals and verticals right after studying in Prague with Josef Suk and Alois Hába (Tek, Toccata). An episode of impressionist sound (Bacchanale, Tri vizije) and subsequently a return to a firm traditional form of the structure and homogeneity in terms of motifs and themes (Svobodi naproti, Žalna glasba, Allegro risoluto-marciale) follow.

\footnotetext{
11 Prim. prvo in tretjo temo, ter končno kadenco na znižani V. stopnji.

12 Prim. tretjo temo in kadenci, v kateri ta akord nadomesti dominantnega, t. 90-91, 192-193.
} 
In Suita za mali orkester (1932) he links together two quite extreme possibilities of "tonally-atonal" polarity. In the melodic field this is indicated by loosely chromatically founded melodic lines with a tendency towards a non-repeating tone content and a fast filling up of chromatic space in contrast to diatonic and clearly tonally-centred lines, some even composed of major triads. The most typical part is the melodic line which is divided into short tonal segments. The simultaneousness ("polyphony") of variable sub textural layers that are differently tonally-centred and of various tone contents is essential in the harmony. In Tek (1935) and Toccata (1936) the entirely filled up (yet loose) chromatic tone space becomes the guideline in horizontals and verticals. Dissonance is emancipated in an equality of all chromatic tones of the horizontals and verticals, which is why the two are Žebre's most radical compositions, melodically as well as harmonically. The essential difference in linking together the horizontal and vertical tone structures that occurs in Žebre's orchestral works is his ballet or symphonic poem consisting of three movements, Dan (1938-1942), known under the name Bacchanale. To get to a result of a homogeneous tone content in both of the space dimensions (following the example of the old tonality) the composer vertically (mostly texturally as well) divides the composition into tone fields. He finds examples for the composition and for the texture which could enable this as efficiently as possible in impressionist composers. When structuring the melody and textural layers the composer mostly uses such scales (with accidentals) that enable "tonal" diversity (including the pentatonic scale, the whole tone scale and the mode). However, the laws of the major-minor (functional) tonality are not valid anymore - individual traditional scales, scale segments, chords or cadences are only old elements in a new system. The tonal material is liberated from old bonds and expanded with new chord structures and interval classes. A similar structural logic stands behind Tri vizije (1939-1943), although the composer limits himself to a total maximum of 8 tones and more often uses whole tone, pentatonic and major-minor structures in melodic lines or other sound layers. In Svobodi naproti (1944), Žalna glasba (1945) and Allegro risoluto-marciale (1949) the idea of tonical and tonal accidentals of the same (diatonic or chromatic) scale of a tone homogeneous segment (simple duple, phrase) is emphasized. Despite the chromatically expanded sound space (that changes its structure from one segment to the next) in all three compositions there can be found sub textural melodic lines and chord structures that are strongly associated with tradition but do not need to follow the old rules of reciprocal effects. 